\title{
Internal and External Factors of Future Returns in the Banking Business: Time Series Analysis of Interrelationship
}

\author{
Kwabena A. Kyei, Albert Antwi \\ Department of Statistics, University of Venda, Limpopo province, South Africa \\ Kyei61@gmail.com, Kwabena.Kyei@univen.ac.za
}

\begin{abstract}
The paper seeks to find the interrelationship between internal and external factors of future returns in the banking business. A multivariate time series regression models are fitted for the dependent variable: return on equity (ROE) against the lag one independent variables, namely: deposit, size, loan, capital, inflation, gross domestic product (GDP) and stock market capitalization (SMC), for ABSA bank; using secondary data, which span from 1998 to 2014 fiscal years. Logarithm transformation of the absolute value of the de-trended data and first differencing at lag one were the smoothing techniques applied to the data. Multivariate time series regression by the least square approach with special consideration of the stepwise method was used in fitting the models to the data. Results indicated that first, there is a positive linear relationship between ROE and loans, a negative linear relationship between ROE and inflation from the differencing techniques; and equally a negative log-linear relationship between ROE and capital as well as a positive log-linear relationship between ROE and ROA for the logarithm de-trend technique.
\end{abstract}

Keywords: Return on Equity; Loan; inflation; market imperfection; multivariate modelling; Return on Assets; lagging

\section{Introduction}

The banking sector of South Africa is one of the various sectors in the economy whose core objective is to maximise future returns while controlling expenses under constrained resources and varied kinds of risks. The banking industry is part of the world's economy and it is controlled and affected by several interwoven processes and factors. These factors and processes have either positive or negative impact on the operations of the industry, hence the need to study how these factors affect future returns of the industry. The profit of any bank is controlled by several variables, which can be classified into internal and external factors. Internal factors are those factors that management policies and decisions have effect on, e.g. size, capital, deposits and loans. The external factors are not affected by management policies and decisions but are controlled by market conditions and sometimes, consumer behavior and government decisions. The study attempts to find the relationship between them.

\section{Methodology}

Data: Historical annual data on the internal factors of bank profitability, from 1998 to 2014, was obtained from ABSA and their website. The external factors were also sourced out from South African Reserve Bank and the World Bank's website. All financial data used are nominated in millions of the South African currency (Rand).

Analysis: Multivariate time series regression with lagged independent and dependent variables by the least square approach was used in fitting models unto the data using Minitab, EVIEWS and SPSS Statistical software (IHS Global, 2015). The backward and forward elimination options in linear regression procedure of Minitab were used to select the variables that needed to be included in the model after which the Least Squares (Gauss-Newton/Marquardt steps) estimation procedure of EVIEWS was used to obtain the estimates of the models. Graphical outputs such us Normal probability plots, Correlogram and scatter plots were obtained using Minitab and IBM SPSS packages.

Preliminary Results: Preliminary analysis indicated that the variables exhibited quadratic pattern in time so the data were de-trended by quadratic models (see the scatterplots below). After the de-trending the data, it was still found out that the variability in the de-trended series increases with the average level of the series so it was necessary to further transform the de-trended series by taking logarithm to the base of ten to stabilise 
this variability (Draper and Smith, 1981; Douglas et al., 2008). Differencing at lag 1 was used as an alternative method to stabilise the data.

Scatter Plots of ROE against Lag-one inflation, loan Capital and ROA for De-Trended and differenced techniques

Figure 1: ROE against lag one Inflation and loan for differenced technique

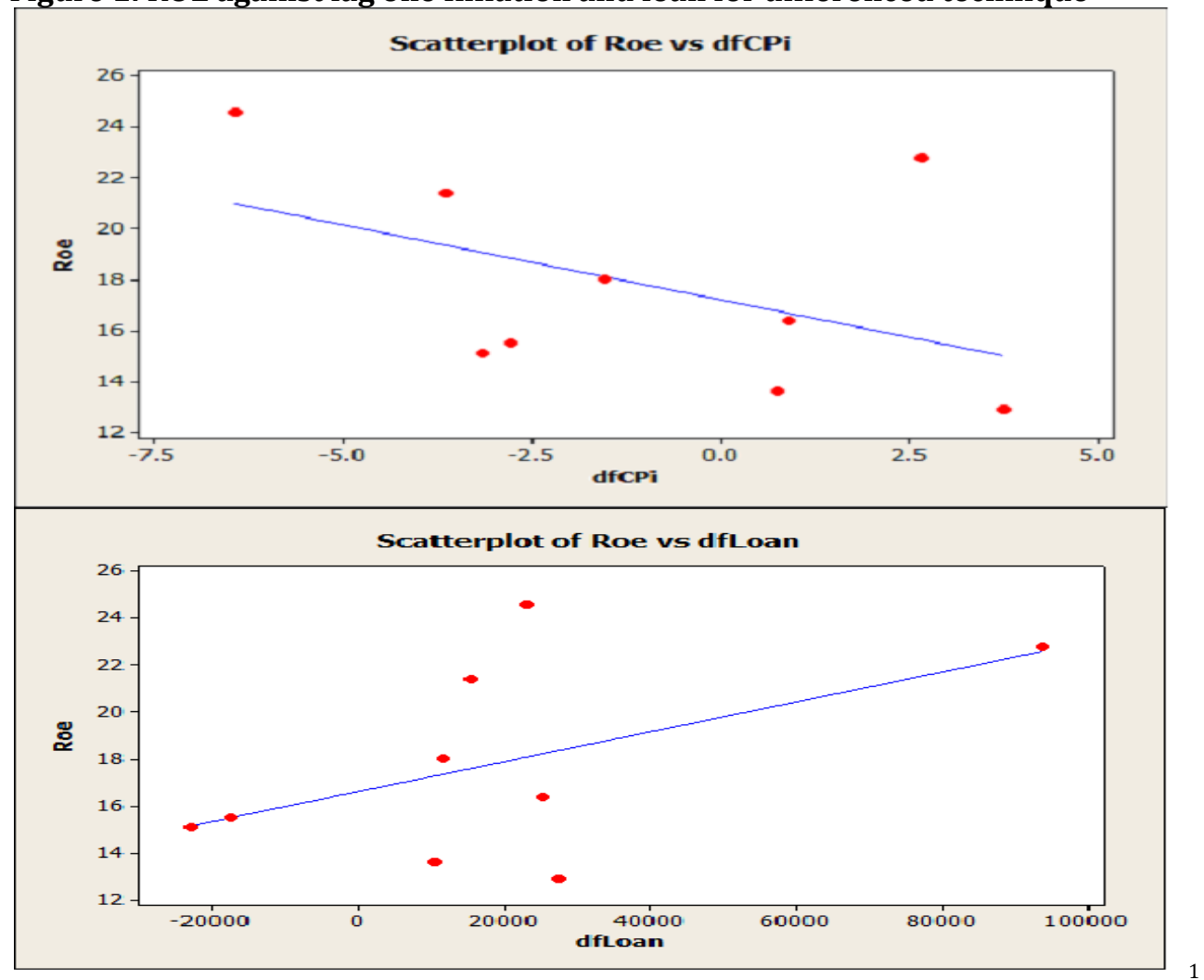

Figure 2: ROE against lag one capital and ROA for logarithm de-trended technique

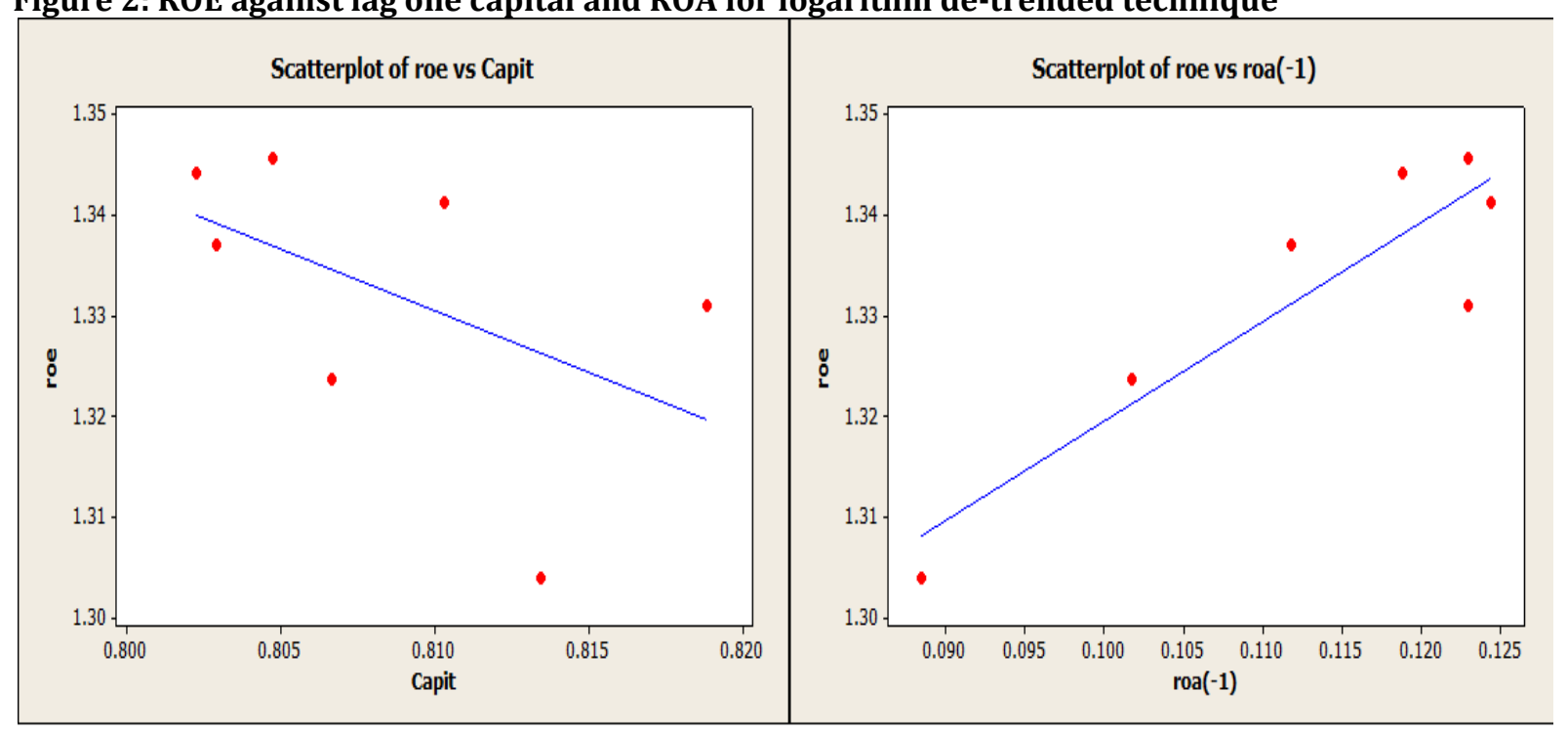


The Models Specifications: Empirical evidence from preliminary analysis of the data and a look at the scatter plots in Figures 1 and 2 suggest that the following models were appropriately fitted onto the data:

\section{Differenced Data Models}

$R O E_{t}=\alpha+\beta\left(d f C P I_{t-1}-d f C P I_{t-2}\right)+\gamma\left(d f \text { Loan }_{t-1}-d f \text { Loan }_{t-2}\right)_{t}+\varepsilon_{t}$

$d f R O E_{t}$ is differenced return on equity at time $t$;

$d f C P I_{t-1}$ and $d f C P I_{t-2}$ are differenced inflation at time lags one and two respectively;

$d f$ Loan $_{t-1}$ and $d f$ Loan $_{t-2}$ are differenced loan at time lags one and two respectively;

$\alpha, \beta$ and $\gamma$ are the parameters to be estimated;

$\varepsilon_{t}$ is the random error term and $t$ represents time, where $t=1998,1999,2000 \ldots$ (Cochrane, 1997).

This model was chosen because, empirical evidence from preliminary analysis and a look at the scatter plot for ROE, CPI and Loan shows a linear association.

De-Trended Log Data Model: The preliminary analysis of the data and a look at the scatter plots of return of equity suggests a log-linear association between return on equity and capital and return on asset. The model chosen is of the form:

$\log \left(d t R O E_{t}-T_{t-1}\right)=\alpha_{2}+\beta_{2} \log \left(d t C A P_{t-1}\right)+\gamma_{2} \log \left(d t R O E_{t-1}\right)+\varpi_{t}$ . .2

Equation 2 can be transformed as

$R O E_{t}=10\left\{\alpha_{2}+\beta_{2} \log \left(d t C A P_{t-1}\right)+\gamma_{2} \log \left(d t R O A_{t-1}\right)+\varpi_{t}\right\}_{+} T_{t-1}$

$T_{t-1}$ is the trend component, which is given by:

$T_{t-1}=R O E_{t-1}-\left(\theta_{0}+\theta_{1} \tau_{t-1}+\theta_{2} \tau_{t-1}^{2}\right)$

$R O E_{t}$ is the original data for return on equity at time

$R O E_{t-1}$ is the original data for return on equity at time at time lag one.

$d t C A P_{t-1}$ is the de-trended natural logarithm capital at time lag one.

$d t R O A_{t-1}$ is the de-trended natural logarithm return on asset at time lag.

$\alpha_{2}, \beta_{2}, \theta_{0}, \theta_{1}, \theta_{2}$ and $\gamma$ are the parameters to be estimated.

$\varpi_{t}$ is the random error term; $t=1998,1999,2000 \ldots$

$T_{\tau}$ represents the residual of the trend in the original equation and $\tau$ represents time with $\tau=1,2,3 \ldots$ where 1998 is the base time, (Douglas et al., 2008).

\section{Results}

The EVIEWS outputs are given in the tables below.

\section{$\underline{\text { ROE analysis of differenced data }}$}


Table 1: Results from differenced data:

\begin{tabular}{|c|c|c|c|c|}
\hline $\begin{array}{l}\text { Dependent Variable } \\
\text { Method: Least Squar } \\
\text { Date: 02/04/16 Tim } \\
\text { Sample: } 19992012 \\
\text { Included observation } \\
\text { ROE }=C(1)+C(2)^{\star} D\end{array}$ & $\begin{array}{l}\text { Aauss-Newt } \\
+\mathrm{C}(3)^{\star} \text { DFL } \\
\end{array}$ & n / Marquarc & ps ) & \\
\hline & Coefficient & Std. Error & t-Statistic & Prob. \\
\hline$C(1)$ & 14.10322 & 0.265173 & 53.18509 & 0.0000 \\
\hline$C(2)$ & -1.264872 & 0.072110 & -17.54081 & 0.0000 \\
\hline $\mathrm{C}(3)$ & 0.000128 & 7.1OE-06 & 18.04008 & 0.0000 \\
\hline R-squared & 0.985828 & Mean depen & at var & 17.81111 \\
\hline Adjusted R-squared & 0.981103 & S.D. depend & t var & 4.189703 \\
\hline S.E. of regression & 0.575936 & Akaike info & erion & 1.995562 \\
\hline Sum squared resid & 1.990216 & Schwarz crit & on & 2.061304 \\
\hline Log likelihood & -5.980031 & Hannan-Qui & criter. & 1.853692 \\
\hline F-statistic & 208.6788 & Durbin-Wats & stat & 2.137329 \\
\hline Prob(F-statistic) & 0.000003 & & & \\
\hline
\end{tabular}

\section{ROE}

Table 2: Confidence interval for the coefficients

Coefficient Confidence Intervals

Date: 02/16/16 Time: 19:48

Sample: 19992012

Included observations: 9

\begin{tabular}{|c|c|c|c|c|c|c|c|}
\hline \multirow[b]{2}{*}{ Variable } & \multirow[b]{2}{*}{ Coefficient } & \multicolumn{2}{|c|}{$90 \% \mathrm{Cl}$} & \multicolumn{2}{|c|}{$95 \% \mathrm{Cl}$} & \multicolumn{2}{|c|}{$99 \% \mathrm{Cl}$} \\
\hline & & Low & High & Low & High & Low & High \\
\hline$C(1)$ & 14.10322 & 13.58794 & 14.61850 & 13.45437 & 14.75208 & 13.12011 & 15.08633 \\
\hline$C(2)$ & -1.264872 & -1.404995 & -1.124749 & -1.441319 & -1.088425 & -1.532216 & -0.997529 \\
\hline C(3) & 0.000128 & 0.000114 & 0.000142 & 0.000111 & 0.000146 & 0.000102 & 0.000154 \\
\hline
\end{tabular}

\section{Table 3: Mean Absolute Percentage Error}

Forecast: ROEF

Actual: ROE

Forecast sample: 19992012

Included observations: 9

\begin{tabular}{ll}
\hline \hline Root Mean Squared Error & 0.470250 \\
Mean Absolute Error & 0.345759 \\
Mean Absolute Percentage Error & 1.957732 \\
Theil Inequality Coefficient & 0.012890 \\
$\quad$ Bias Proportion & 0.000000 \\
Variance Proportion & 0.003568 \\
Covariance Proportion & 0.996432 \\
\hline \hline
\end{tabular}

\section{ROE analysis of logarithm de-trended data}

2DFCPI and DFLOAN are the differenced lag one variables of inflation and loan respectively. ROE is the original return on equity. 
Table 4: Results from logarithm de-trended data

Dependent Variable: ROE

Method: Least Squares (Gauss-Newton / Marquardt steps)

Date: 02/06/16 Time: 12:37

Sample: 20012007

Included observations: 7

$\mathrm{ROE}=\mathrm{C}(1)+\mathrm{C}(2)^{\star} \mathrm{CAPIT}+\mathrm{C}(3)^{*} \mathrm{ROA}{ }_{1}$

\begin{tabular}{lrlrr}
\hline \hline & Coefficient & Std. Error & t-Statistic & Prob. \\
\hline \hline C(1) & 2.060579 & 0.007269 & 283.4889 & 0.0000 \\
C(2) & -1.033453 & 0.008922 & -115.8266 & 0.0000 \\
C(3) & 0.949855 & 0.004035 & 235.3920 & 0.0000 \\
\hline \hline & 0.999946 & Mean dependent var & 1.332426 \\
R-squared & 0.999919 & S.D. dependent var & 0.014752 \\
Adjusted R-squared & 0.000133 & Akaike info criterion & -14.72124 \\
S.E. of regression & $7.03 E-08$ & Schwarz criterion & -14.74442 \\
Sum squared resid & 54.52434 & Hannan-Quinn criter. & -15.00776 \\
Log likelihood & 37138.22 & Durbin-Watson stat & 2.255209 \\
F-statistic & 0.000000 & & & \\
Prob(F-statistic) & & & &
\end{tabular}

Table 5: Confidence interval for the Coefficients - log. De-trended

Coefficient Confidence Intervals

Date: 02/06/16 Time: 12:39

Sample: 20012007

Included observations: 7

\begin{tabular}{|c|c|c|c|c|c|c|c|}
\hline \multirow[b]{2}{*}{ Variable } & \multirow[b]{2}{*}{ Coefficient } & \multicolumn{2}{|c|}{$90 \% \mathrm{Cl}$} & \multicolumn{2}{|c|}{$95 \% \mathrm{Cl}$} & \multicolumn{2}{|c|}{$99 \% \mathrm{Cl}$} \\
\hline & & Low & High & Low & High & Low & High \\
\hline$C(1)$ & 2.060579 & 2.045083 & 2.076074 & 2.040398 & 2.080760 & 2.027113 & 2.094044 \\
\hline$C(2)$ & -1.033453 & -1.052474 & -1.014432 & -1.058226 & -1.008681 & -1.074533 & -0.992374 \\
\hline$C(3)$ & 0.949855 & 0.941253 & 0.958458 & 0.938652 & 0.961059 & 0.931277 & 0.968434 \\
\hline
\end{tabular}

Table 6: Mean absolute percentage error - log. De-trended

Forecast: ROEF

Actual: ROE

Forecast sample: 20012007

Included observations: 7

\begin{tabular}{ll}
\hline \hline Root Mean Squared Error & 0.000100 \\
Mean Absolute Error & $8.34 \mathrm{E}-05$ \\
Mean Absolute Percentage Error & 0.006274 \\
Theil Inequality Coefficient & $3.76 \mathrm{E}-05$ \\
$\quad$ Bias Proportion & 0.000000 \\
$\quad$ Variance Proportion & 0.000013 \\
$\quad$ Covariance Proportion & 0.999987 \\
\hline
\end{tabular}

\begin{tabular}{ll}
\multicolumn{2}{l}{ Table 7: Quadratic trend estimates } \\
\hline Parameter & Estimate \\
\hline$\theta_{0}$ & 13.45 \\
$\theta_{1}$ & 2.253 \\
$\theta_{2}$ & -0.1454 \\
\hline
\end{tabular}

${ }^{3}$ ROA_1_ and CAPIT are the de-trended log lag one variables of original return on asset and capital respectively. ROE is the de-trended $\log$ lag of original return on equity data. $\theta_{0}, \theta_{1}$ and $\theta_{2}$ are the quadratic pattern parameters 
Results- Differencing techniques: In Table 1 , the adjusted R-squared is 0.985828 , indicating that about $99 \%$ of the total variance in the ROE has been accounted for. This indicates that the model is good fit to the data. The mean absolute percentage error in Table 3 is 1.957732, which is quite small confirming the assertion that the model is adequate. The F-statistic of 208.6788 and Prob. (F-statistic) of 0.000003 indicates that the model is significant at $95 \%$ level of confidence. Since the p-values of all the estimated coefficients are less than 5\%, alpha level, we fail to reject the null hypothesis that the coefficients are zero (Medenhall \& Schaeffer, 1973). We therefore conclude that all the three coefficients of the models for ROE are significant in the estimation of the dependent variables. This is also attested to by the fact that a look at Table 2, indicates that all the coefficients are within the 95\% confidence interval. Among the estimated coefficients of the model, the two factors, namely, inflation and loans are very important at $5 \%$ significant level. Other factors were found not to be significant in the estimation of ROE, as they were not entered during the stepwise method of linear regression modelling.

Results- De-Trended Logarithm technique: From Table 4, the adjusted R-squared is 0.999946, indicating that about $99.995 \%$ of the total variance has been accounted for. This indicates that the model is very good fit onto the data (Kleinbaum et al., 1998; Mazerolle, 2004). In addition, the mean absolute percentage error of 0.006274 , from Table 6 , for the model is very small. This confirms the assertion that the model is very good. A look at the $p$-value of the F-statistic is zero, indicating that the model is significant at $95 \%$ level of confidence. In addition, since the $p$-values of all the coefficients are less than $5 \%$ alpha level, we fail to reject the null hypothesis that the coefficients are zero. It can therefore be concluded that all the coefficients in the models are significant in the estimation of the dependent variables. This is also attested to by the fact that a look at Table 5 indicates that all the coefficients are within the $99 \%$ confidence interval. All the estimated coefficients are equally important at 5\% significance level when using the associated models for forecast since the $p$ values of all of them are zero. All other factors were found to be insignificant at $5 \%$ level of significant in the estimation as they were removed during the stepwise method of linear regression modelling (Draper \& Smith, 1981).

\section{Discussion}

Models of Differenced Data: The relationships between return on equity and loans were found to be positive linear and that of return on equity and inflation was negative linear. The result is consistent with previous findings of return on equity, loans by Molyneux \& Thornton (1992), Bikker \& Hu (2002), and Gul et al. (2011), findings by Duraj \& Moci (2015), and Ben \& Kandil (2009) on the relationship between inflation and return on asset. However, the same studies by Duraj and Moci (2015) on loans and profitability and by Gul et al. (2011) on inflation and profitability were inconsistent with the result of this study. When loan is increased by two million rand and inflation also increases by $2 \%$, there will be an increase of $0.0022 \%$ and a decrease of $21.86 \%$ in return on equity respectively. Higher loans are therefore not risky to return on equity component of future returns while higher inflationary rate is very risky to return on equity and aggregate profitability.

Models of De-Trended Logarithm and Inverse Square Root: Negative log-linear relationship exists between return on equity and capital and positive log-linear relationship exist between return on equity and return on asset. In a related study, Havrylchyk \& Emilia (2006) findings were contrary to the findings of this study in terms of the direction of association between capital and profits of banks while findings by Yong \& Christos (2012), Molyneux \& Thornton (1992), Bikker \& Hu (2002), and Gul et al. (2011) on capital and profitability were consistent with the findings of this study. It can be deduced from the coefficients of these relationships that simultaneous increasing of return on asset and capital by $2 \%$ will deflate return on equity by $1.78 \%$ and inflated by $0.45 \%$ respectively. Contrary to the deduction that an increase in return on asset will cause a deflation in return on equity, there will be inflation in return on equity by some percentage points instead. The reason is that, return on asset is a component of future returns therefore the higher its positive change, the higher its relative contribution to future returns. For instance if return on asset is increased by $10 \%$ and $20 \%$ there will be corresponding decreases in return on asset by $0.178 \%$ and $0.356 \%$. These decreases in return on asset are comparatively less than their corresponding increases in net interest margin hence the net contributions of a positive change in return on asset is favourable to aggregate future returns. It 
can therefore be concluded that a positive change in capital and return on asset are not risky to return on equity and aggregate future returns.

Summary of Analysis: The following table (Table 8) gives us a summary of the forecast made from this study.

Table 8: Summary of Forecasting Model

\begin{tabular}{lllllllllll}
\hline YEAR & ROA\% & ROE\% & NIM\% & SIZE & CAPITAL\% & LOANS & GDP & MC & INF & $\tau$ \\
\hline \multirow{2}{*}{2012} & 1.09 & 13.6 & 3.87 & 807939 & 9.009839 & 572840 & 2.2 & 7841303 & 5.75 & 15 \\
2013 & 1.08 & 13.5 & 3.64 & 792635 & 7.22388 & 600126 & 2.2 & 9752279 & 5.77 & 16 \\
2014 & 1.08 & 16.9 & 3.83 & 814061 & 7.238524 & 619860 & 1.5 & 10718200 & 6.13 & \\
\hline
\end{tabular}

Using the information from Table 8, we calculate the estimates for ABSA models as follows:

$$
\begin{aligned}
& R O E_{t}=1 \mathrm{O}^{\{2.060579-1.033453 \log (7.22388)+0.949855 \log (1.08)\}} \\
& \quad+\{(13.45+2.253(16)-0.1454(16))\} \\
& =17.25049 \\
& R O E_{t}=14.10322-1.264872(6.13-5.77)+0.000128(619860-600126) \\
& \quad=16.17382
\end{aligned}
$$

Comparing the estimated, ROE values above to the actual 2014 ROE values; there was an error of estimation of about $2.07 \%$ for the logarithm de-trended technique and $4.3 \%$ error for the differencing technique. This indicates that the use of the estimated ROE models to describe the inter-relationships between the variables of future returns was appropriate.

\section{Conclusion}

Our results indicated that first; there was a positive linear relationship between ROE and loans, a negative linear relationship between ROE and inflation from the differencing techniques; and equally a negative loglinear relationship between ROE and capital as well as a positive log-linear relationship between ROE and ROA for the logarithm de-trended data. It was further deduced from these relationships that high lag one values of inflation has negative net aggregate effect on future returns. Capital was also found to have negative impact on future returns. High ROA and loans increase future returns. All other variables considered in these models were insignificant for estimating on future returns of ABSA. They were consequently removed from the models during the estimation process.

\section{References}

Ben, N. S. \& Kandil, M. (2009). The impact of capital requirements on banks' cost of intermediation and performance: The case of Egypt. Journal of Economics and Business, 61, 70-89.

Bikker, J. A. \& Hu, H. (2002). Cyclical Patterns in Profits, Provisioning and Lending of Banks and Procyclicality of the New Basle Capital Requirements. BNL Quarterly Review, 221, 143-175.

Cochrane, J. H. (1997). Time Series for Macroeconomics and Finance. University of Chicago, 40-41.

Douglas, C. M., Cheryl, L. J. \& Murat, K. (2008). Introduction to Time Series. Analysis and Forecasting Wiley \& Sons. Inc. Hoboken. New Jersey, 12-139.

Draper, N. R. \& Smith, H. (1981). Applied Regression Analysis. John Wiley \& Sons. 2nd Edition, 5-22, 70-102, 218-275. 
Duraj, B. \& Moci, E. (2015). Factors influencing the bank profitability - Empirical evidence from Albania. Asian Economic and Financial Review ISSN (e): 2222 6737/ISSN (p): 2305-2147. Available at: http://www.aessweb.com/journals/5002

Gul, S., Irshad, F. \& Zaman, K. (2011). Factors Affecting Bank Profitability in Pakistan. The Romanian Economic Journal, XIV(39), 61-87

Havrylchyk, O. \& Emilia, J. (2006). Profitability of foreign banks in Central and Eastern Europe: Does the entry mode matter, Bank of Finland, Bofit Discussion Papers 5.

IHS Global Inc. (2015). EVIEWS 9 User's Guide II. ISBN: 978-1-880411-27-8

Kleinbaum, D. G., Kupper, L. L. \& Nisan, A. (1998). Applied Regression Analysis and other Multivariate Methods. Duxbury Press, An imprint of Brooks/Cole publishing company. 3rd Edition, 88-95, 112-119.

Mazerolle, M. J. (2004). Making sense out of Akaike's Information Criterion (AIC): its use and interpretation in model selection and inference from ecological data. Available at: http://www.theses.ulaval.ca/2004/21842/apa.html (2de13).

Medenhall, W. \& Schaeffer, R. L. (1973). Mathematical statistics with Applications. Duxbury press by Wadsworth publishing company in, Belmort, California 94002; 383-386.

Molyneux, P. \& Thornton, J. (1992). Determinants of European Bank Profitability; a Note. Journal of Banking and Finance, 16, 1173- 78.

Newton, P. \& Bookboon.com (2015). Understanding financial performance. $1^{\text {st }}$ Edition. ISBN: 978-87-4030819-8.

Yong, T. A. \& Christos, F. (2012). Bank profitability and GDP growth in China: A Note. Journal of Chinese Economics and Business Studies, 10(3), 267-273. ISSN 1476-5284

ABSA: Http://www.absa.co.za.

World Bank: Http://www.worldbank.org. 